\title{
The impact of social problem skills on academic motivation by means of Covid-19 fear
}

\author{
A SEM Model: Social Problem Solving, Covid-19, Academic Motivation
}

\author{
H. Deniz Günaydın ${ }^{1}$ (D)
}

Accepted: 19 March 2021 / Published online: 1 April 2021

(C) The Author(s), under exclusive licence to Springer Science+Business Media, LLC, part of Springer Nature 2021

\begin{abstract}
Recent studies have investigated the relationship between the social problem-solving skills and academic motivation; nevertheless, new studies should examine the relationships between the social problem solving and academic motivation taking the effect of Covid-19 fear into consideration. As a result of this, in this study, it was aimed to a construct structural equation model by which the impacts of social problem-solving skills on academic motivation by means of Covid-19 fear were studied. Therefore, 513 university students participated in the study and completed Social Problem-Solving Inventory-Short Form, the Fear of Covid-19 Scale, and Academic Motivation Scale. The SEM model analysis indicated that rational problem solving, negative orientation to problem, impulsive/careless style and avoidant style predicted $\% 15$ of the Covid-19 fear. Altogether rational problem solving, negative orientation to problem, impulsive/careless style, avoidant style, positive orientation to problem and Covid-19 fear explained $\% 32$ of the academic motivation.
\end{abstract}

Keywords Social-problem solving $\cdot$ Positive orientation to problem $\cdot$ Negative orientation to problem $\cdot$ Rational problem solving . Impulsive/careless style $\cdot$ Avoidant style $\cdot$ Covid- 19 fear $\cdot$ Academic motivation

\section{Introduction}

One of the evolving worldwide challenges in coping with contagious infections is to manage the new 2019 Covid-19 virus, which was announced a pandemic by the World Health Organization on March 11, 2020 (World Health Organization 2020) and spread rapidly amid 221 countries/ territories in the world with over 111.748 .647 million affirmed cases and over 2.474.091 deaths at the time of research writing (February 21, 2021; Worldometer, 2020). During the pandemic lockdown, the schools and businesses were closed down, people started working from home and alongside, fear of infection, and financial anxiety (Brooks et al. 2020; Murphy et al. 2020; Salisu and Akanni 2020). Therefore, having exceptionally elevating infection percentage and comparatively high-level of mortality, people obviously began distressing

H. Deniz Günaydın dgunaydin@gmail.com

1 Department of Psychology, Faculty of Social Human Sciences, Konya Food and Agriculture University, Konya, Turkey about the Covid-19 (Baud et al. 2020; Maben and Bridges 2020).

Fear of contacting people infected by Covid-19 has been revealed by the researchers (Lin 2020). Accordingly, the pandemic of the Covid-19 and its outcomes caused individuals' emotional and psychological reactions such as fears, concerns, and worries amid people all over the world (Ahorsu et al. 2020; Fitzpatrick et al. 2020; Li et al. 2020; Murphy et al. 2020; Reznik et al. 2020; Salisu and Akanni 2020; Sasaki et al. 2020; Wang et al. 2020). Due to a high degree of anxiety, people cannot think logically and rationally when reacting to Covid-19, leading negative consequences in various life settings. However, the potential effect of a fear, stress or anxiety concerning the current pandemic should be examined in other contexts such education.

Regarding the educational context, several universities experienced closures because of the pandemic-linked alterations. In addition, in some situations, university students have been moved out of campus to minimize the risk of transmission in crowded environments. Face-to-face courses were shifted to an online teaching format to keep away from being contaminated from other students. Therefore, numerous undergraduates were adversely influenced by work and economic 
shortfalls (Perz et al. 2020). In general, student university life became more unstable and worrying (Hartocollis 2020). One survey in the USA indicated that $91 \%$ of university students stated increased anxiety or fear (Active Minds 2020). The research outcomes concerning student experiences during the pandemic show that the students have troubles adapting to the uncertainties that were caused due to the Covid-19.

The influence of Covid-19 on the academic motivation has been recently researched by several investigators (D'Alise 2020; Masaali 2007; Pasion et al. 2020; Zaccoletti et al. 2020). Academic motivation was considered to be an important element for student achievement, particularly at the university level (Orsini et al. 2015). Beck (2004) defined academic motivation as the rationales for students' attending to, commitments, and attempts concerning learning and accomplishing at school setting, which focused solely on the reasons why individuals decided and continue university education (Muza and Muhammad 2020; Schunk et al. 2008). Academic motivation involves the desire to do something well in a particular area and to self-assess one's performance (Masaali 2007). Besides, attitudes and behaviors pertaining to academic motivation involve maintaining difficult assignments, working intensely to learn to new things, and selecting effort requiring tasks. Overall, academic motivation is an important predisposition to pursue an academic assignment successfully and to assess students' current performance.

The researchers (D'Alise 2020; Pasion et al. 2020; Zaccoletti et al. 2020) disclosed that Covid-19 had significant effects on the academic motivation. A recent cross-country research (Zaccoletti et al. 2020) demonstrated that there was a considerable reduction in academic motivation of Portuguese and Italian students due to the home restriction period due to the Covid-19 pandemic. Furthermore, in this period, the absence of control over the learning process or fewer preferences and the reduced feeling of capability and autonomy to perform academic oriented learning tactics because of shifting from face-to-face lessons to online lessons led to reduce academic motivation (Kim and Frick 2011).

Social problem-solving skills were also viewed as significant predictors of the academic motivation (Baker 2003; Rodriguez-Fornells and Maydeu-Olivares 2000). Social problem solving was defined as self-guided intellectual social behavioral process by which an individual struggles to discover or determine adaptive methods of dealing with problematic circumstances that were confronted in daily lives (D'Zurilla and Nezu 1982). One of the basic assumptions of social problem-solving process is that problem solving is a general coping strategy that facilitates and maintains general competence and adaptation (D'Zurilla 1990). While problem solving skills or problem-solving styles are evaluated with different problem names such as problem solving, intrapersonal, interpersonal, impersonal, and social problems, social problemsolving skills include two independent processes; 1 . Problem orientation and 2. Problem solving styles. Problem orientation consists of two dimensions: positive problem orientation and negative problem orientation; problem solving styles consist of three dimensions: rational problem solving, impulsive/ careless problem-solving style, and avoidant problemsolving style (D'Zurilla et al. 2004).

Additionally, social problem-solving skills had a significant obvious impact on academic performance and achievement (Baker 2003). Studies on social problem solving (Rodriguez-Fornells and Maydeu-Olivares 2000) revealed that effective self-assessed problem solving was associated with better academic performance. Accordingly, it was established that academic motivation perform a crucial role in learning consequences (Deci and Ryan 1991). However, in the process of Covid-19 pandemic, new studies are needed to examine the effect of social problem solving on academic motivation.

The issues of social problem-solving skills are associated with the other variables such as Covid-19 fear as well as academic motivation. While social competencies and problemsolving skills could have a significant positive impact on academic motivation, the conditions that occur due to Covid-19 could negatively affect academic motivation (Ryan and Deci 2017). A recent study (Zaccoletti et al. 2020) has suggested that fears and anxieties due to Covid-19 have affected students' academic motivation in a negative way. However, although there was some evidence of learning habits of its students during, for example, Covid-19 (Trung et al. 2020), there is insufficient evidence as to how the Covid-19 pandemic is restrictive and what variables are effective on academic motivation and performance. In this context, the measures taken by national governments to contain the spread of coronavirus negatively affected the academic motivation levels of students and learning in general. Given the challenges posed by the measures taken due to the pandemic, it is likely that there will be further decrease in the academic motivation of students during the Covid-19 pandemic (Zaccoletti et al. 2020). Therefore, it is important to investigate Covid-19 fear and factors that affect academic motivation.

Overall, Covid-19 has ever-increasing impacts on university students and their academic motivation. Now, because of the Covid-19 pandemic, academics has focused more on academic motivation amongst university students studying within online learning settings. While university students instantaneously attempt to adjust to the new educational conditions, it is, therefore, essential to examine the adverse impacts of pandemic on academic motivation. Thus, the current study aims to assess the relationships between social problem solving, Covid-19 fear and academic motivation. Accordingly, the overall aim of the existing study is to construct a structural model of academic motivation in the era of Covid-19 epidemic, and thus to establish the impacts of problem solving, and Covid-19 fear on academic motivation. 


\section{Research Model and Hypotheses}

The research model investigated in the present article is presented in Fig. 1 below. This model assesses the effects of the social problem-solving skills and Covid-19 fear on academic motivation. The kinds of the social problem-solving skills in the study include positive orientation to problem, negative orientation to problem, rational problem solving, impulsive/ careless style and avoidant style. Each construct in the existing study model and the hypotheses are in detail provided below.

\section{Effect of Covid-19 Fear}

Some of the studies conducted in the era of pandemic have suggested that Covid-19 fear have had impact on students' academic motivation (D'Alise 2020; Pasion et al. 2020; Zaccoletti et al. 2020). It was revealed that the Covid-19 fear has led people to experience psychological consequences including anxiety and fear in various parts of the world (Ahorsu et al. 2020; Murphy et al. 2020; Reznik et al. 2020; Wang et al. 2020), decreasing students' academic motivation and academic performance (Pasion et al. 2020; Zaccoletti et al. 2020). In another words, the students who live higher level of Covid-19 fear have lower level of academic motivation. Correspondingly, the subsequent hypothesis is suggested:

H1. Covid-19 fear has a negative effect on academic motivation.

\section{Effects of Positive Orientation to Problem}

Studies showed that there was a positive correlation between Positive problem orientation and overall academic performance GPA (Rodriguez-Fornells and Maydeu-Olivares
2000). Positive orientation to a problem positively supports academic motivation and academic performance as positive problem orientation helps to decrease the stressfulness of everyday academic difficulties and enable higher motivation to tackle harder projects effectively, which upsurges that person's capability (D'Zurilla 1990). Besides, it is considered that positive perspective can behave as an efficient mediator in the direction of the having higher happiness especially in the framework of Covid-19 (Yıldırım and Güler 2021). Thus, positive orientation to problem is regarded as a substantial psychological source of strength to protect oneself against the Covid-19 related mental problems. Based on the research and suggestions above, we created the following hypotheses:

H2a. Positive orientation to problem has a negative effect on Covid-19 fear.

H2b. Positive orientation to problem has a positive effect on academic motivation.

\section{Effects of Rational Problem Solving}

A significant positive association between rational problemsolving and academic performance is suggested by the researchers, indicating that students use rational problemsolving style could be better academic performers due to the nature of rational problem-solving style to make better decisions (Trunzo et al., 2014). So, rational problem-solving style has potential to have significant effect on academic motivation. In addition, it is considered that rational problem-solving used in the era of Covid-19 could support the psychological health and personal strength (Meng 2020). Therefore, we suppose that rational problem-solving style will have a positive effect on Covid-19 fear. The outcomes mentioned above- led us to establish the ensuing hypotheses:

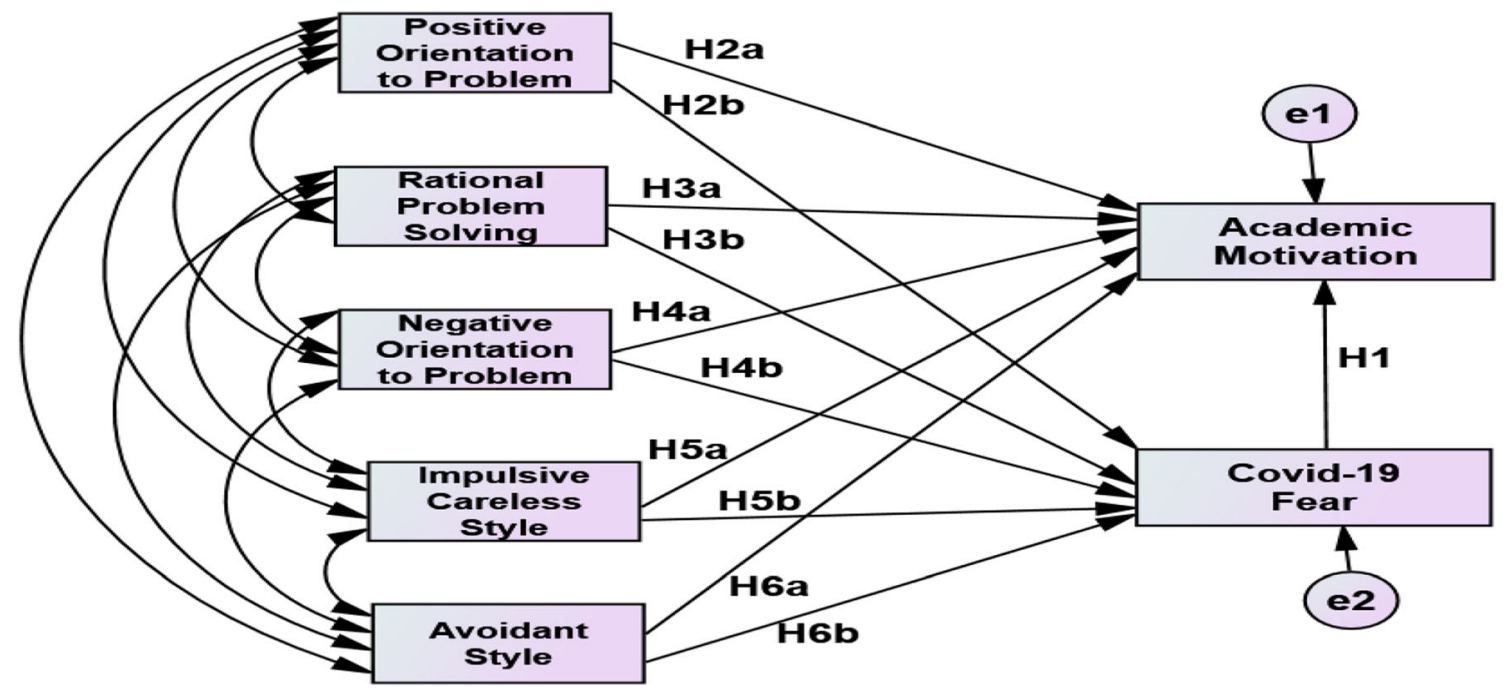

Fig. 1 Research model 
H3a. Rational problem solving has a negative effect on Covid-19 fear.

H3b. Rational problem solving has a positive effect on academic motivation.

\section{Effects of Negative Orientation to Problem}

Negative problem orientation was linked with students' academic performance (McCabe et al. 1999; Rodriguez-Fornells and Maydeu-Olivares 2000). Therefore, negative orientation to a problem may have a negative impact on academic motivation. In addition to this, negative orientation to problem may boost the level of Covid-19 fear. Thus, negative emotions accompanying the negative orientation to problem during Covid-19 can result in psychological problems such as anxiety, depression and distress (Mamun and Griffiths 2020), indicating the substantial relationship between negative orientation to problem and Covid-19 fear. Consequently, the following hypotheses were offered withing the present research:

H4a. Negative orientation to problem has a positive effect on Covid-19 fear.

H4b. Negative orientation to problem has a negative effect on academic motivation.

\section{Effects of Impulsive/Careless Style}

Studies indicate a significant positive relationship between impulsive/ careless problem-solving style and poorer academic performance as well as academic motivation (RodriguezFornells and Maydeu-Olivares 2000; Trunzo et al., 2014). Consistent with this, earlier research in university learning environment uncovered problem-solving skills, especially impulsive/carelessness style was a significant predictor better academic performance (D'Zurilla 1990). On the other hand, impulsiveness/carelessness style is described by impetuous, careless, hasty and inadequate problem-solving attempts (Maydeu-Olivares and D'Zurilla (1996). Those who tend to use impulsive / careless style use create a limited solution options and act according to the first solution in their minds (D'Zurilla et al. 2004). We consider that these people may experience more difficulties concerning Covid-19 outcomes. In view of these observations, the subsequent hypotheses were suggested:

H5a. Impulsive/Careless style has a positive effect on Covid-19 fear.

H5b. Impulsive/Careless style has a negative effect on academic motivation.

\section{Effects of Avoidant Style}

A significant negative relationships between avoidance problem solving style and academic motivation was indicated, suggesting that avoidant students may have weaker academic performance (Trunzo et al., 2014). People with avoidant styles were found to study less (Gore and Rogers 2010). Furthermore, low fear during the pandemic was associated with joining in avoidant performances (Witte and Allen 2000). Additionally, Gan et al. (2004) established that people using avoidant style were more adaptive when they confronted with overwhelming stressors such as pandemic as they incline to avoid or disregard the source of stress. Concerning the current literature, the following hypotheses were established:

H6a. Avoidant style has a negative effect on Covid-19 fear.

H6b. Avoidant style has a negative effect on academic motivation.

\section{Method}

\section{Participants}

The research instruments were performed to university students who studied in various departments such as mental health, medicine, education, engineering, architecture, management within the Konya province of Turkey in 2021. The online survey measures were completed by 593 volunteer university students. 80 incomplete survey forms were excluded from the study and finally, the data analysis was executed on data from 513 participants, whose were between 18 and 37 years old. While 420 (\%81.9) of the survey participants were female, 93 (\%18.1) of the participants were male students. In terms of students' grades, 284 (\%55.4) of the students were the first-year students, 108 of them (\%21.1) were the second-year students, 58 of them (\%11.3) were the thirdyear students and 63 of them (\%12.2) were the fourth year student.

\section{Data Collection Instruments}

\section{Social Problem-Solving Inventory-Short Form (SPSI)}

SPSI Short Form is a 25 -item inventory developed by D'Zurilla et al. (2002) to determine social problem-solving skill levels and adapted to Turkish by Çekici and Sonay Güçray (2012). The SPSI Short Form consists of five subscales: positive orientation to the problem (POP), negative orientation to the problem (NOP), rational problem solving 
(RPS), impulsive/careless style (IIS), and avoidant style (AS). The Inventory is five-point Likert type scale, ranging from 0 (not suitable at all) to 4 (completely suitable). The lowest score obtained from the scale is 0 and the highest score is 100. High scores indicate that social problem-solving skill is "at a good level", while low scores indicate "low level" social problem-solving skill. The inter reliability of the JPS was calculated by means of Cronbach Alpha analysis. In the study by Çekici and Sonay Güçray (2012), the internal consistency coefficient values of each subscale of SPSI-SF were $=.81$ for POP,$=.76$ for NOP, $=.74$ for RPS $=0.75,=.61$ for IIS and for AS $=0.81$. In the current study, Cronbach alpha values were 0.79 for PO, 0.80 for POSY, 0.76 for Rational Problem Solving, 0.61 for impulsive/careless style, and 0.83 for Avoidant Style.

\section{The Fear of Covid-19 Scale (FCS)}

The Fear of COVID-19 Scale was developed by Ahorsu et al. (2020) and adapted to Turkish by Satici et al. (2020). The scale is a 5-point Likert type instrument ranging from 1 (Strongly disagree) to 5 (Strongly agree) and all 7 items of the scale are positive scored. There is no reverse scored item in the scale. The scale is scored between 7 and 35 and a high score shows that the Covid pandemic fear level is high. In the Turkish validity and reliability study of the scale, the Cronbach Alpha value was found as $\alpha=0.82$. In this study, the Cronbach Alpha value of the scale was determined as $\alpha=$ 0.89 .

\section{Academic Motivation Scale (AMS)}

AMS was developed by Bozanoğlu (2004) to determine students' academic motivation. AMS is 5-point Likert type scale, ranging from 1 (definitely not suitable) to (definitely suitable). AMS has three sub-scales: Self-Transcendence (7 items), Using Knowledge (6 items) and Discovery (7 items). The highest score that can be obtained from the scale is 100 and the lowest score is 20. Higher score from the scale means higher academic motivation. In the original study, the Cronbach Alpha values were $\alpha=0.76$ for Self-
Transcendence, $\alpha=0.72$ for Using Knowledge, $\alpha=0.73$ for Discovery and $\alpha=0.88$ for overall AMS. 82 . In the present study, the Cronbach Alpha values were $\alpha=0.84$ for SelfTranscendence, $\alpha=0.80$ for Using Knowledge, $\alpha=0.75$ for Discovery and $\alpha=0.91$ for overall AMS.

\section{Data Analysis}

The structural equation modeling (SEM) method was used to verify the study model in the current study. The research data was examined by means of SPSS Amos 22 (IBM-SPSS Inc., Chicago, IL, USA). The SEM analysis was performed in the study because of the fact that it has power to evaluate casual associations among study variables with various items (Jöreskog \& Sörbom, 1996). Moreover, the structural equation model was used to measure the relationships that were postulated in the current study model. Positive orientation to problem, negative orientation to problem, rational problem solving, impulsive/careless style, avoidant style, Covid-19 fear were independent variables, and academic motivation was a dependent variable. Finally, a model regarding the associations among these variables and academic motivation was created by the investigator.

The assumptions of SEM were observed before study data was examined. The skewness and kurtosis values were computed to determine the normality assumption of the study data. The values that are acceptable for asymmetry/skewness and kurtosis should be between -2 to +2 to obtain a normal univariate normal data distribution. The researcher found that the values were in an acceptable range for a normal distribution of the research data. Besides, mean, median and mode values were close to each other showing that the data was normally distributed (Table 1). Furthermore, the outliers were evaluated, and eighty outliers were eliminated from the research data. Consequently, the linearity analysis was conducted, and it was seen that the associations between the research variables were quite linear. The power analysis was computed by means of $\mathrm{G}$ power analysis. It was revealed that sample size needed for the research should be 250 . Accordingly, 513 university students participated in the study. It is suggested (Harrington 2009; Kline 2005) that 200 or more participants are necessary to

Table 1 Normality Assumptions of the Study Data

\begin{tabular}{llllllll}
\hline & $\begin{array}{l}\text { Positive Orientation } \\
\text { to Problem }\end{array}$ & $\begin{array}{l}\text { Negative Orientation } \\
\text { to Problem }\end{array}$ & $\begin{array}{l}\text { Rational Problem } \\
\text { Solving }\end{array}$ & $\begin{array}{l}\text { Impulsive / Careless } \\
\text { Style }\end{array}$ & Avoidant Style & $\begin{array}{c}\text { Covid-19 Fear } \\
\text { Academic } \\
\text { Motivation }\end{array}$ \\
\hline Mean & 17.85 & 14.35 & 19.33 & 11.27 & 9.90 & 76.12 \\
Median & 18.00 & 14.00 & 20.00 & 11.00 & 9.00 & 15.00 & 75.35 \\
Mode & 20.00 & 13.00 & 20.00 & 10.00 & 7.00 & 7.00 & 79.00 \\
Skewness & -.270 & .236 & -.552 & .370 & 1.011 & 0.634 & -.567 \\
Kurtosis & -.229 & -.535 & .364 & .087 & .561 & -.265 & .860 \\
\hline
\end{tabular}


conduct a model study showing the significance of the associations and to get an acceptable outcomes.

\section{Findings}

We have conducted descriptive data and Pearson correlation analyses to find out overall scores and associations among the variables. We present the means, standard deviation and correlation coefficients concerning the research variables in the following table (Table 1). The Pearson correlation data analysis indicated positive significant correlations between positive orientation to problem, rational problem solving, Covid19 fear and academic motivation, while a negative significant correlation between negative orientation to problem, impulsive/careless style, avoidant style, and academic motivation. In addition, data analysis showed that there was a positive significant correlation between negative orientation to problem, impulsive/careless style, avoidant style and Covid19 fear, while there was a negative significant correlation between positive orientation to problem and Covid-19 fear. However, data analysis revealed no significant correlation between rational problem solving and Covid-19 fear (Table 2).

Structural equation modeling (SEM) was conducted in order to assess the fit of the present model. Root Mean Square Residuals (RMR), Goodness of Fit Index (GFI), Adjusted Goodness of Fit Index (AGFI), Normed Fit Index (NFI), Incremental Fit Index (IFI), Tucker-Lewis index (TLI), and Comparative fit index (CFI) were investigated. It was suggested by Bentler (1990) and Bollen (1989) that the model fit index values are expected be between 0.00 and 1.00, and further they suggest that these index values should be bigger than 0.90 so that a model should be considered to be an acceptable model fit. In addition to these SEM index values, the Root Mean Square Error of Approximation (RMSEA) is interpreted as supplementary indication of a fit model and a RMSEA root value which is below 0.05 indicates a good model fit (Browne and Cudeck 1993). Similarly, the $\mathrm{x}^{2} / \mathrm{df}$ value is expected to be less than 3 for an acceptable SEM model (Kline 2005). Consequently, the model modification was assessed taking these index values into consideration.

The suggested structural equitation model (Fig. 1) was explored so as to assess the effects of observed (endogenous) variables on academic motivation. The outcomes of the analyses revealed that the suggested model was acceptable considering the subsequent criteria, and the model was discovered to have a strong fit: $\mathrm{x}^{2}=8.12, \mathrm{df}=4, \mathrm{x}^{2} / \mathrm{df}=2.03, p=0.08$, $\mathrm{RMR}=0.93, \mathrm{GFI}=0.99, \mathrm{AGFI}=0.97, \mathrm{NFI}=0.99, \mathrm{IFI}=99$, $\mathrm{TLI}=0.98, \mathrm{CFI}=0.99$, and RMSEA $=0.04$ (Fig. 2).

Overall, the SEM data analysis disclosed that positive orientation to problem $(\beta=0.37)$ and rational problem solving ( $\beta=0.25$ ) had positive impact on academic motivation. However, negative orientation to problem, impulsive/ careless style and avoidant style didn't have significant effects on academic motivation. Additionally, rational problem solving $(\beta=0.18)$, negative orientation to problem $(\beta=0.40)$, impulsive/careless style $(\beta=0.12)$ had positive impact and avoidant style $(\beta=-0.09)$ had negative effect on Covid-19 fear, while positive orientation to problem did not have any significant effect on Covid-19 fear. Rational problem solving, negative orientation to problem, impulsive/careless style and avoidant style (by way of Covid-19 fear, $(\beta=0.13)$ ) had a positive effect on academic motivation. Rational problem solving, negative orientation to problem, impulsive/careless style and avoidant style predicted $\% 15$ of the Covid-19 fear. Altogether rational problem solving, negative orientation to problem, impulsive/careless style, avoidant style, positive orientation to problem and Covid-19 fear explained $\% 32$ of the academic motivation.

\section{Discussion}

\section{Discussion of the Theoretical Model}

The present study has examined the model that indicate the relationships between problem solving skills and styles such as positive orientation to problem, negative orientation to

Table 2 Means and correlation coefficients of variables

\begin{tabular}{|c|c|c|c|c|c|c|c|c|c|}
\hline & Mean & SD & 1 & 2 & 3 & 4 & 5 & 6 & 7 \\
\hline 1.Positive Orientation to Problem & 17.85 & 3.84 & - & $-.572^{* *}$ & $.575^{* *}$ & $-.162^{* *}$ & $-.429^{* *}$ & $-.153^{* *}$ & $.494^{* *}$ \\
\hline 2. Negative Orientation to Problem & 14.35 & 4.17 & & - & $-.287^{* *}$ & $.288^{* *}$ & $.488^{* *}$ & $.345^{* *}$ & $-.272^{* *}$ \\
\hline 3.Rational Problem Solving & 19.33 & 3.28 & & & - & $-.388^{* *}$ & $-.355^{* *}$ & .047 & $.473^{* *}$ \\
\hline 4.Impulsive / Careless Style & 11.27 & 3.55 & & & & - & $.397^{* *}$ & $.130^{* *}$ & $-.201^{* *}$ \\
\hline 5.Avoidant Style & 9.91 & 4.22 & & & & & - & $.093^{*}$ & $-.303^{* *}$ \\
\hline 6.Covid-19 Fear & 16.12 & 6.77 & & & & & & - & $.091^{*}$ \\
\hline 7.Academic Motivation & 75.35 & 12.09 & & & & & & & - \\
\hline
\end{tabular}

** $p<0.01,{ }^{*} p<0.05$ 


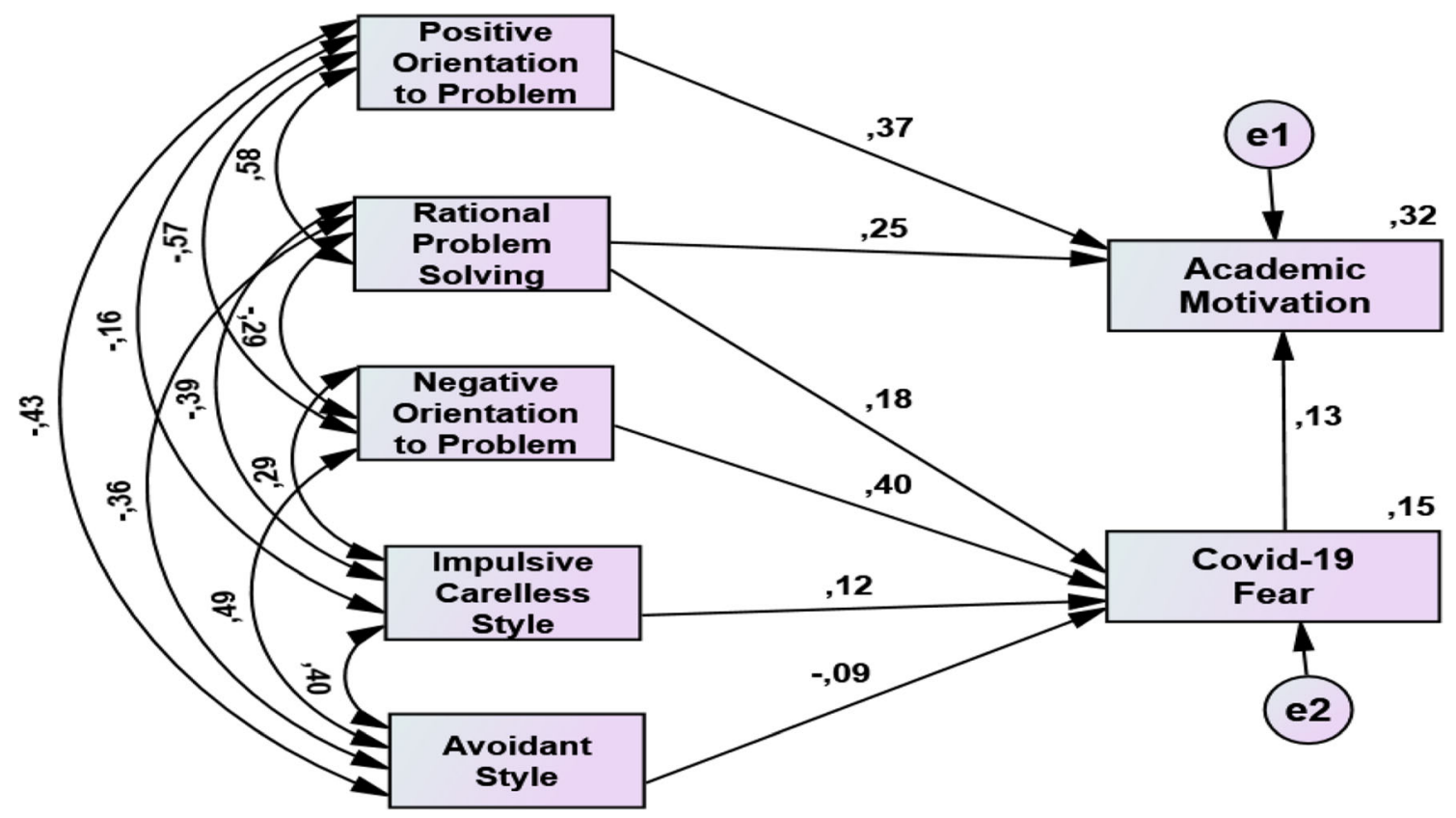

Fig. 2 Testing the results of the model

problem, rational problem solving, impulsive/careless style and avoidant, Covid-19 fear and academic motivation first in the era of pandemic, even though some of the studies revealed individual relationships between the problem-solving skills and academic motivation. In brief, in the current research, structural model of academic motivation combining the problem-solving skills, Covid-19 fear and motivation to study during the pandemic. Moreover, we explored the degree to which of the variables explained academic motivation directly or by way of mediating variables. Overall, problem-solving skills including rational problem solving, negative orientation to problem, impulsive/careless style, and avoidant style predicted $\% 15$ of Covid-19 fear, while it was unveiled that that positive orientation to problem, rational problem solving, and Covid-19 fear explained \%32 of the academic motivation.

In particular, the analysis in the current study yielded that Covid-19 fear positively affected academic motivation as opposed to hypothesized in this study and the recent study (Zaccoletti et al. 2020). This shows that university students in the present study had higher level of academic motivation in the period of Covid-19, which could be explained by the fact that the participants' positive problem orientation and rational problem-solving average scores were higher than the average scores of negative problem orientation, impulsive / inattentive problem-solving style, and avoidant problemsolving style. Besides, participants' average Covid-19 fear score were quite low, showing that they had low level of fear to negatively affect their academic motivation.

In terms of the association between problem solving skills and academic motivation, it was found that positive orientation to problem had a positive effect on the academic motivation, in line with related studies (D'Zurilla 1990; Rodriguez-Fornells and Maydeu-Olivares 2000; Trunzo et al., 2014). This may be because of the fact that positive problem orientation to problems may reduce everyday stress and enable motivation to solve the problems efficiently, which can improve that a student's competency in turn (D'Zurilla 1990). It can be considered that higher level of competence has potential to support academic motivation. In other words, positive orientation to problem may enable university students to have higher level of motivation to challenge more difficult projects efficiently because positive orientation has potential to increase their capability and capacity. However, positive orientation to problem did not have any significant impact on Covid-19 fear, in contrast to findings by Yldırım and Güler (2021). The sources of difference can be due to the fact that participants in this study had lower average scores of Covid-19 fear compared to other studies, where these studies suggested that positive orientation is a considerable psychological source of strength to keep oneself and upsurges higher happiness particularly in the times of Covid-19.

In addition, the study results showed that rational problem solving was a significant positive predictor of the academic motivation, which is supported by the findings of Trunzo et al. (2014). Rational problem-solving skills are considered to yield to improved academic performance because rational problem-solving style by its nature include making better decisions, which create a natural potential to enhance university students' academic motivation. Furthermore, rational problem-solving skill in the present study was a positive significant predictor of Covid-19 fear in contrast to the hypothesis assumed in this study and the study by Meng (2020), who 
discovered that rational problem-solving supported the psychological health and personal strength, having potential to decrease fear of Covid-19. Finally, the participants who had higher rational problem-solving score may have more realistic view about pandemic that led them to have higher fear of Covid-19 fear.

When the relationship between negative orientation to problem and academic motivation was analyzed, it was found that negative orientation was not a significant predictor of academic motivation, which could be because the participants in this study low average score of negative orientation to problem. This finding is in line with findings by Trunzo et al. (2014) but differs from the findings by RodriguezFornells and Maydeu-Olivares (2000) who found a negative relationship between negative orientation to problem and academic performance. In terms of the association between Covid-19 and negative orientation to problem, negative orientation was a negative predictor of Covid-19 fear, which means that negative orientation to problem may increase the level of Covid-19 fear. Consequently, the participants with higher level of average negative orientation scores may experience negative emotions such as anxiety, depression and distress more frequently during COVID-19, resulting in psychological problems (Mamun and Griffiths 2020.

Also, impulsive / careless problem-solving style did not have any significant effect on academic motivation, different from D'Zurilla (1990) and Rodriguez-Fornells and MaydeuOlivares (2000), who found that impulsive / careless problemsolving was a significant predictor of academic motivation. In addition, Trunzo et al. (2014) suggested that impulsive i.e., less considerate and thoughtful students had poorer academic performers. The source of difference may be again because the participants in this study had low level of impulsive / careless problem-solving scores. From the point of Covid-19, impulsive / careless problem-solving style was a negative significant predictor of Covid-19 fear. It is suggested that Covid-19 pandemic may trigger 'mortality salience' leading to impulsive, distorted, irrational and assertive behaviors (Steele, 2020). In line with this, impulsiveness/carelessness style is illustrated by hasty, careless, impetuous and ineffective behaviors (Maydeu-Olivares and D'Zurilla (1996). In addition, people who utilize impulsive / careless style tend to create a limited options and perform the first solution they have (D'Zurilla et al. 2004). Accordingly, we suppose people who use impulsive / careless problem-solving style may have higher level of Covid-19 fear.

The data analysis indicated that avoidant problem-solving style was not a significant predictor of academic motivation. However, Trunzo et al. (2014) disclosed that avoidant problemsolving style was a negative significant predictor of academic motivation, indicating that more avoidant students could have weaker academic performance. Gore and Rogers (2010) established that avoidant students tended to study less. Contrary to the other problem-solving skills, avoidant style was a negative significant predictor of Covid-19 fear. Likewise, low level of Covid-19 fear was linked with more avoidant performances (Witte and Allen 2000). Additionally, Gan et al. (2004) determined that people who utilized avoidant problem style apted to disregard the source of stress were considered to be more adaptive when they experienced overwhelming stressors like pandemic as they.

Consequently, the study revealed that social problem-solving skills, postive orientation to problem and rational problem solving together with Covid-19 fear were key factors in appraising academic motivation. The study outcomes suggest that the social problem-solving skills, and Covid-19 could help us comprehend university students' academic motivation at the times of the corona pandemic. As a whole, the current SEM model uncovered the relationships among the independent variables and academic motivation both individually and as a whole.

\section{Limitations and Implications}

The current research offers a theoretical structure and logical judgments to clarify the effects of social problem-solving skills and Covid-19 fear on academic motivation. The present study suggests a novel model; however, it has some research limitations by default. First of all, the study sample included university students that studied in Konya / Turkey, which can limit the generalizability of the research results. Thus, future studies could gather data from a different regions in Turkey or across a variety of cultures in the world. Second of all, in the existing study, the correlation between social problem solving, Covid-19 fear, and academic motivation was analyzed. Nonetheless, Covid-19 fear and academic motivation can have relationships with other variables such as learning styles, self-efficacy, academic achievement, academic stress, engagement, social stigma and other psychological factors including anxiety, stress, distress and depression. Therefore, forthcoming studies are suggested to include the potential variables mentioned above into their models. Third of all, the literature regarding especially social problem-solving skills, Covid-19 fear and academic motivation is fairly inadequate. Hence, further studies should make the association between these variables clearer. Finally, although the model outcomes were quantitatively supported, additional structural models can utilize different relationships analyses such as regression analyses.

Data Availability The data that support the outcomes of the present study are available on demand from the corresponding author.

\section{Declarations}

Ethical Statement I also declare that study measures were reviewed by the committee of ethics that is located in Konya Food and Agricultural 
University and results of inspections indicate that instruments and application of the study were in line with widely accepted ethical principles.

Informed Consent The author obtained consent from participants who took part in the research and the researcher followed the requirements of the Declaration of Helsinki. Accordingly, the researcher informed the participants about of the aim of study and guaranteed that the participants' responds would kept anonymous and they would only be used for study purposes.

Conflict of Interest I here assert that there is not any conflict of interest among authors and other parties regarding the present research.

\section{References}

Active Minds (2020). COVID-19 impact on college student mental health. https://www.activeminds.org/wpcontent/uploads/2020/04/ Student-Survey-Infographic.pdf.

Ahorsu, D. K., Lin, C. Y., Imani, V., Saffari, M., Griffiths, M. D., \& Pakpour, A. H. (2020). The Fear of COVID- 19 scale: Development and initial validation. International Journal of Mental Health and Addiction, 1. https://doi.org/10.1007/s11469020-00270-8.

Baker, S. R. (2003). A prospective longitudinal investigation of social problem-solving appraisals on adjustment to university, stress, health, and academic motivation and performance. Personality and Individual Differences, 35(3), 569-591.

Baud, D., Qi, X., Nielsen-Saines, K., Musso, D., Pomar, L., \& Favre, G. (2020). Real estimates of mortality following COVID-19 infection. The Lancet Infectious Diseases., 20, 773. https://doi.org/10.1016/ S1473-3099(20)30195-X.

Beck, R. C. (2004). Motivation: Theories and principles (5th ed.). New York: Prentice Hall.

Bentler, P. M. (1990). Comparative fit indexes in structural models. Psychological Bulletin, 107(2), 238-246. https://doi.org/10.1037/ 0033-2909.107.2.238.

Bollen, K. A. (1989). A new incremental fit index for general structural equation models. Sociological Methods \& Research, 17(3), 303316. https://doi.org/10.1177/0049124189017003004.

Bozanoğlu, İ. (2004). Akademik güdülenme ölçeği: Geliștirmesi, geçerliği, güvenirliği [Academic motivation scale: Development, validity, reliability]. Ankara Üniversitesi Eğitim Bilimleri Fakültesi Dergisi [Ankara University Journal of Educational Sciences], 37(2), 83-98.

Brooks, S. K., Webster, R. K., Smith, L. E., Woodland, L., Wessely, S., Greenberg, N., \& Rubin, G. J. (2020). The psychological impact of quarantine and how to reduce it-rapid review of evidence. Lancet, 395(10227), 912-920. https://doi.org/10.1016/S0140-6736(20) 30460-8.

Browne, M. W., \& Cudeck, R. (1993). Alternative ways of assessing model fit in: Bollen KA, long JS, eds. Testing structural equation models. Beverly Hills, CA: Sage, 136-162. https://doi.org/10.1177/ 0049124192021002005.

Çekici, F., \& Sonay Güçray, S. (2012). Problem çözme terapisine dayalı beceri geliştirme grubunun üniversite öğrencilerinin sosyal problem çözme becerileri öfkeyle ilișkili davranıș ve düșünceler ile sürekli kayg1 düzeylerine etkisi [The effect of problem solving therapybased skill development group on social problem solving skills of university students on anger-related behaviors and thoughts and trait anxiety levels]. Çukurova Üniversitesi Sosyal Bilimler Enstitüsü Dergisi, [Çukurova University Journal of Social Sciences Institute] 21(2), 103-128.
D'Alise, D. (2020). The relationship among learning styles, academic self-efficacy and motivation. An empirical study during Covid-19. Retrieved from https://www.researchgate.net/publication/ 343417870 on [21February 2021].

Deci, E. L., \& Ryan, R. M. (1991). A motivational approach to self: Integration in personality. In R. A. Dienstbier (Ed.), Current theory and research in motivation, Vol. 38. Nebraska Symposium on Motivation, 1990: Perspectives on motivation (p. 237-288). University of Nebraska Press.

D'Zurilla, T. J., \& Nezu, A. (1982). Social problem solving in adults. In Advances in cognitive-behavioral research and therapy (pp. 201274). Academic press.

D'Zurilla, T. J. (1990). Problem-solving training for effective stress management and prevention. Journal of Cognitive Psychotherapy: An International Quarterly, 4, 327-354.

D'Zurilla, T. J., Nezu, A. M., \& Maydeu-Olivares, A. (2002). Manual for the social problem solving inventory - revised (SPSI-R). North Tonawanda: Multi-Health Systems.

D'Zurilla, T. J., Nezu, A. M., \& Maydeu-Olivares, A. (2004). What is social problem solving? Meaning, models, and measures. In E. C. Chang, T. J. D'Zurilla, \& L. J. Sanna (Eds.), Social problem solving: Theory, research, and training (pp. 11-27). Washington, DC: American Psychological Association.

Fitzpatrick, K. M., Harris, C., \& Drawve, G. (2020). Living in the midst of fear: Depressive symptomatology among US adults during the COVID-19 pandemic. Depression and Anxiety, 37(10), 957-964.

Gan, Y., Liu, Y., \& Zhang, Y. (2004). Flexible coping responses to severe acute respiratory syndrome-related and daily life stressful events. Asian Journal of Social Psychology, 7, 55-66. https://doi.org/10. 1111/j.1467839X.2004.00134.x.

Gore, J. S., \& Rogers, M. J. (2010). Why do I study? The moderating effect of attachment style on academic motivation. The Journal of Social Psychology, 150(5), 560-578.

Harrington, D. (2009). Confirmatory factor analysis. Oxford university press.

Hartocollis, A. (2020). Scattered to the winds, college students mourn lost semester. New York Times. https://www.nytimes.com/2020/05/27/ us/coronavirus-college-mental-health.html.

Jöreskog, K. G., \& Sörbom, D. (1996). PRELIS 2 user's reference guide: A program for multivariate data screening and data summarization: A preprocessor for LISREL. Scientific Software International.

Kim, K. J., \& Frick, T. W. (2011). Changes in student motivation during online learning. Journal of Educational Computing Research, 44(1), $1-23$.

Kline, R. B. (2005). Principles and practice of structural equation modeling 2nd ed (p. 3). New York: Guilford.

Li, S., Wang, Y., Xue, J., Zhao, N., \& Zhu, T. (2020). The impact of Covid-19 epidemic declaration on psychological consequences: A study on active Weibo users. International Journal of Environmental Research and Public Health, 17(6), 2032. https:// doi.org/10.3390/ijerph17062032.

Lin, C.-Y. (2020). Social reaction toward the 2019 novel coronavirus (COVID-19). Social Health and Behavior, 3(1), 1-2. https://doi. org/10.4103/SHB.SHB_11_20.

Maben, J., \& Bridges, J. (2020). Covid-19: Supporting nurses' psychological and mental health. Journal of Clinical Nursing., 29, 2742 2750. https://doi.org/10.1111/jocn.15307.

Mamun, M. A., \& Griffiths, M. D. (2020). First COVID-19 suicide case in Bangladesh due to fear of COVID-19 and xenophobia: Possible suicide prevention strategies. Asian Journal of Psychiatry, 51, 102073.

Masaali, S. (2007). Relationship between reading study and academic achievement among students in IU. [Doctorate Dissertation, Isfahan: Khorasgan Islamic Azad University]. 
Maydeu-Olivares, A., \& D'Zurilla, T. J. (1996). A factor-analytic study of the social problem-solving inventory: An integration of theory and data. Cognitive Therapy and Research, 20, 115-133.

McCabe, R. E., Blankstein, K. R., \& Mills, J. S. (1999). Interpersonal sensitivity and social problem-solving: Relations with academic and social self-esteem, depressive symptoms, and academic performance. Cognitive Therapy and Research, 23(6), 587-604.

Meng, X. L. (2020). COVID-19: A massive stress test with many unexpected opportunities (for data science). Special Issue 1-COVID-19. Retrieved from https://hdsr.mitpress.mit.edu/pub/17a2t45s/release/ 1?readingCollection $=0181 \mathrm{~d} 53 \mathrm{~b}$ on [24 February, 2021].

Murphy, D., Williamson, C., Baumann, J., Busuttil, W., \& Fear, N. T. (2020). Exploring the impact of COVID-19 and restrictions to daily living as a result of social distancing within veterans with preexisting mental health difficulties. BMJ Mil Health, 1-5.

Muza, S. H., \& Muhammad, S. (2020). Academic stress and academic motivation among undergraduate students of Kebbi State University of Science and Technology, Aliero Kebbi state, Nigeria. International Journal of Advanced Academic Research (Arts, Humanities and Education), 6(12).

Orsini, C., Binnie, V., Evans, P., Ledezma, P., Fuentes, F., \& Villegas, M. J. (2015). Psychometric validation of the academic motivation scale in a dental student. Journal of Dental Education, 971-98.

Pasion, R., Dias-Oliveira, E., Camacho, A., Morais, C., \& Franco, R. C. (2020). Impact of COVID-19 on undergraduate business students: A longitudinal study on academic motivation, engagement and attachment to university. Accounting Research Journal. https://doi.org/10. 1108/ARJ-09-2020-0286, ahead-of-print.

Perz, C. A., Lang, B. A., \& Harrington, R. (2020). Validation of the Fear of COVID-19 scale in a US College sample. Int J Ment Health Addiction. https://doi.org/10.1007/s11469-020-00356-3.

Reznik, A., Gritsenko, V., Konstantinov, V., Khamenka, N., \& Isralowitz, R. (2020). Covid-19 fear in Eastern Europe: Validation of the Fear of Covid-19 scale. International journal of mental health and addiction, 1. https://doi.org/10.1007/s11469-020-00283-3.

Rodriguez-Fornells, A., \& Maydeu-Olivares, A. (2000). Impulsive/ careless problem-solving style as predictor of subsequent academic achievement. Personality and Individual Differences, 28, 639-645.

Ryan, R. M., \& Deci, E. L. (2017). Self-determination theory: Basic psychological needs in motivation, development, and wellness. Guilford Publications.

Salisu, A. A., \& Akanni, L. O. (2020). Constructing a global fear index for the COVID-19 pandemic. Emerging Markets Finance and Trade, 56(10), 2310-2331.

Sasaki, N., Kuroda, R., Tsuno, K., \& Kawakami, N. (2020). Workplace responses to COVID-19 associated with mental health and work performance of employees in Japan. Journal of Occupational Health, 62(1), e12134.

Satici, B., Gocet-Tekin, E., Deniz, M. E., \& Satici, S. A. (2020). Adaptation of the Fear of COVID-19 scale: Its association with psychological distress and life satisfaction in Turkey. International Journal of Mental Health Addiction. https://doi.org/10.1007/ s11469-020-00294-0.

Schunk, D. H., Pintrich, P. R., \& Meece, J. L. (2008). Motivation in education. Saddle River, NJ: Pearson.

Steele, H. (2020). COVID-19, fear and the future: An attachment perspective. Clinical Neuropsychiatry, 17(2), 97-99.

Trung, T., Hoang, A. D., Nguyen, T. T., Dinh, V. H., Nguyen, Y. C., \& Pham, H. H. (2020). Dataset of Vietnamese student's learning habits during COVID-19. Data in Brief, 30, 105682.

Trunzo, J. J., Samter, W., Morse, C., McClure, K., Kohn, C., Volkman, J. E., \& O'Brien, K. (2014). College students' use of energy drinks, social problem-solving, and academic performance. Journal of Psychoactive Drugs, 46(5), 396-401.

Wang, C., Pan, R., Wan, X., Tan, Y., Xu, L., Ho, C. S., \& Ho, R. C. (2020). Immediate psychological responses and associated factors during the initial stage of the 2019 coronavirus disease (COVID-19) epidemic among the general population in China. International Journal of Environmental Research and Public Health, 17, 1729. https://doi.org/10.3390/ijerph17051729.

Witte, K., \& Allen, M. (2000). A meta-analysis of fear appeals: Implications for effective public health campaigns. Health Education \& Behavior, 27(5), 591-615. https://doi.org/10.1177/ 109019810002700506.

World Health Organization. (2020). WHO Director General's Opening Remarks at the Media Briefing on COVID-19. [Press release]. https://www.who.int/dg/speeches/detail/who-director-general-sopeningremarks-at-the-media-briefing-on-covid-19\%2D\%2D-11march-2020.

Yıldırım, M., \& Güler, A. (2021). Positivity explains how COVID-19 perceived risk increases death distress and reduces happiness. Personality and Individual Differences, 168, 110347.

Zaccoletti, S., Camacho, A., Correia, N., Aguiar, C., Mason, L., Alves, R. A., \& Daniel, J. R. (2020). Parents' perceptions of student academic motivation during the COVID-19 lockdown: A cross-country comparison. Frontiers in Psychology, 11.

Publisher's Note Springer Nature remains neutral with regard to jurisdictional claims in published maps and institutional affiliations. 